\section{Rat race in PD}

\section{By Lauren Martz, Staff Writer}

The Michael J. Fox Foundation for Parkinson's Research didn't waste any time putting recently published knockout rat technology to work..$^{1,2}$ The foundation and Sigma-Aldrich Corp. have partnered to develop models of Parkinson's disease and hope to make five rat models available for research use within a year.

In July, Sigma-Aldrich, in collaboration with Sangamo BioSciences Inc., Open Monoclonal Technology Inc. and the Medical College of Wisconsin, published the first targeted rat gene knockout, in Science. The knockout was produced using zinc finger nuclease (ZFN) technology developed by Sangamo. ZFNs induce targeted, double-stranded DNA breaks that can snip out specific genes of interest in a genome. ${ }^{3}$

The foundation and Sigma-Aldrich think PD is an ideal application for the technology because the disease lacks models and because rats provide a good representation of the human neurological system.

There is no mouse model of PD that accurately recapitulates the human condition.

"Two aspects go into finding the right models: the ability to measure neurological defects and the ability to show symptomatically what is seen in Parkinson's disease," said Kirsten Carlson, associate director of research programs at the Michael J. Fox Foundation.

"While we know that it isn't possible to exactly replicate the human disease, we want to develop a behavioral manifestation of what is seen in the disease," she told SciBX. "Good symptomatic models and good models that show what's going on in the brain do exist, but the Holy Grail of animal models of Parkinson's disease is to develop one that captures both."

Philip Simmons, global marketing and business development manager at Sigma Advanced Genetic Engineering (SAGE) Labs, said the fact that rats are smarter than mice and have both behavioral and cognitive characteristics that are similar to humans is important for replicating the features of PD and for measuring the efficacy of treatments.

"It was natural to consider neurobiological and neurodegenerative conditions for the knockout rats based on the superior brain functions of these animals," he told SciBX. "It could be more predictive for Parkinson's disease or Alzheimer's disease than mouse models allow."

Carlson agreed. "We might be able to develop the rat into a more suitable model," she said. "Rats are also larger organisms, which allows researchers to harvest more tissue from them in preclinical research and can allow for imaging studies that might be more difficult in smaller animals."

\section{Knockout quintet}

Under Sigma-Aldrich's deal with the foundation, which includes a research grant to SAGE, the company will knock out five genes implicated in the cause of the disease: leucine-rich repeat kinase 2 (LRRK2), $\alpha$-synuclein (SNCA), DJ-1 (PARK7), Parkin (PARK2) and PTEN induced putative kinase 1 (PINK1).

In genetic association studies, mutations in all five genes have shown significant associations with PD. PARK7, PARK2 and PINK1 code for neuroprotective proteins, and loss of function mutations have been identified as possible causal factors for PD. ${ }^{4-6}$ Mutations causing overexpression of LRRK2 and SNCA, the latter of which is involved in the production of pathogenic Lewy bodies, contribute to genetic development of PD. ${ }^{7,8}$

The foundation does not expect all the models to recapitulate the disease. "For some genes, it is overexpression that is linked to the disease, so knocking them out might not help create an accurate model but could shed light on the biological function of the genes and lead to new drug targets," said Carlson. "In other cases, the disease is caused by a reduction or deletion in gene activity, and the hope is that deleting these genes could create a good model of Parkinson's."

The process for creating the rats involves injecting a ZFN reagent into one-day-old rat embryos. The embryos are transplanted into a pseudo-pregnant mother, and the rat is born with a knockout of a desired gene.

"This strategy has been around for a while and we have spent a lot of time perfecting it," said Simmons. "The beauty is that you use the ZFN to create a very special mutation-the ZFN reagent splices the DNA at a targeted site to delete the gene, and the reagent is eventually removed from the animal. It makes what is basically a natural deletion that can be passed along to offspring."

Philip Gregory, CSO and VP of research at Sangamo, added that ZFNs can save time versus embryonic stem cell knockout techniques. "We don't have to first do embryonic stem cell transduction, then generate chimeric mice and breed for heterozygosity," he said. "We eliminate these steps with the ZFN technology by directly treating the embryo."

Simmons told SciBX that Sigma has created the ZFN reagents and is now starting to inject them into rat embryos. "Within a year, we expect to have a large enough colony to ship out the animals to researchers, including those associated with the Michael J. Fox Foundation," he said.

"Making our models broadly accessible to the scientific community has always been Sigma's practice. We will offer simple label licenses to make these animals available for research use," said David Smoller, president of the research biotech business unit of SigmaAldrich.

Under a 2007 agreement, Sangamo granted Sigma-Aldrich rights to use its ZFN technology to develop laboratory reagents. This month, the companies expanded the deal. Sigma-Aldrich now has exclusive rights to develop and distribute not only ZFN-modified cell lines for commercial production of protein pharmaceuticals but also 
certain ZFN-engineered transgenic animals for commercial applications in exchange for undisclosed milestones and royalties.

The foundation made a research grant to SAGE Labs.

Martz, L. SciBX 2(41); doi:10.1038/scibx.2009.1522

Published online Oct. 22, 2009

REFERENCES

1. Geurts, A. et al. Science 325, 433 (2009)

2. Edelson, S. SciBX 2(27); doi:10.1038/scibx.2009.1100

3. Katada, H. \& Komiyama, M. et al. Chembiochem 10, 1279-1288 (2009)
4. Bonifati, V. et al. Science 299, 256-259 (2002)

5. Lucking, C. et al. N. Engl. J. Med. 342, 1560-1567 (2000)

6. Valente, E. at al. Science 304, 1158-1160 (2004)

7. West, A. et al. Proc. Natl. Acad. Sci. USA 102, 16842-16847 (2005)

8. Kirilk, D. et al. J. Neurosci. 22, 2780-2791 (2002)

COMPANIES AND INSTITUTIONS MENTIONED

Medical College of Wisconsin, Milwaukee, Wis.

The Michael J. Fox Foundation for Parkinson's Research, New York, N.Y.

Open Monoclonal Technology Inc., Palo Alto, Calif.

Sangamo BioSciences Inc. (NASDAQ:SGMO), Richmond, Calif. Sigma-Aldrich Corp. (NASDAQ:SIAL), St. Louis, Mo. 